\title{
ANÁLISE COMPARATIVA DA COMUNICAÇÃO DA MARCA ENTRE O E-COMMERCE E A LOJA FÍSICA
}

Maiara Gizeli Dallazen Camillo

Universidade Federal de Santa Catarina

Marília Matos Gonçalves

Universidade Federal de Santa Catarina

marilinhamt@gmail.com

Luiz Salomão Ribas Gomez

Universidade Federal de Santa Catarina

salodesigner@gmail.com

Maylon Do Amaral

Universidade Federal de Santa Catarina

Resumo: A definição de uma marca por uma empresa tem como intenção, de maneira geral, identificar produtos e fidelizar clientes. Para empresas que possuem pontos de venda on-line e físicos, esses fatores auxiliam na integralização das suas comunicações, para buscar transmitir a mesma mensagem aos consumidores. Essa conexão entre ambientes on-line e físico tem tornado a empresa ainda mais competitiva, já que aumenta e diversifica os ambientes de compra. Nesta linha, esse artigo aborda a importância da gestão da marca para a integração dos canais de venda de uma empresa. Para isso, apresenta teorias do branding, abrangendo a comunicação integrada da marca no auxilio da percepção do consumidor. Conhecendo-se essa importância, então, este trabalho apresenta um estudo de caso onde são analisadas, de maneira comparativa, as comunicações aplicadas no e-commerce e em uma loja física, ambas da marca que denominaremos de Empresa A. Durante o processo de pesquisa foi possível observar a preocupação da empresa com a gestão do design da marca e a grande integração dos quesitos de branding entre o e-Commerce e o loja física. Foi possível também compreender que é possível uma aplicação pratica da teoria sobre a gestão do design da marca.

Palavras-chave: Branding, Varejo, Gestão do design

Abstract: The definition of a trademark by a company's intention, in general, identify products and customer loyalty. For companies that have online outlets and physical, these factors help in the payment of their communications, seek to convey the same message to consumers. This connection between online environments is physical has made the company even more competitive as it increases and diversifies the purchase 
environments. In this line, this article discusses the importance of brand management for the integration of sales channels of a company. For this presents branding theories, including the integrated brand communication in the help of consumer perception. Knowing this importance, then, this paper presents a case study to be analyzed, in a comparative way, communications applied in e-commerce and a physical store brand of Company A. During the search process could be observed company's concern with the management of brand design and great integration of branding questions among e-commerce and physical store. It was also possible to understand that it is possible for a practical application of the theory of management of brand design.

Keywords: Branding, Store, Design Management

\section{INTRODUÇÃO}

Estão sendo transformadas as maneira das empresas ofertarem seus produtos e serviços. Cada vez mais, algum fator de diferenciação caracteriza seu modelo de negócios. Muitas das novas oportunidades surgem através da oferta de qualidade, preço e design. Informações presentes no Diagnóstico do Design Brasileiro (2014), afirmam que no mercado brasileiro o design tem se mostrado de grande importância para as empresas, agindo como um elo integrador entre a indústria e o mercado. Ele é considerado um ativo para o desempenho empresarial, determinando conquistas de mercado, diferenciação de produtos e serviços, redução de custos na produção e muitos outros fatores.

Comunicar de maneira adequada a marca se faz necessário para destacar os produtos ou serviços de determinada empresa. Quando essa comunicação é aplicada no varejo, ela se torna um mecanismo eficiente para criar uma atmosfera de identificação da empresa. Isso pode ocorrer tanto para o varejo online, quanto físico. Contribuindo para a diferenciação dos concorrentes do mesmo seguimento e caracterizando a empresa como uma referência no mercado (CHAMMA; PASTORELO, 2007). Criar uma marca, com o intuito de condensar essas informações em tangíveis e intangíveis em uma é o processo de branding.

\section{DESENVOLVIMENTO}

\subsection{A gestão do design na construção de uma identidade corporativa}

Gerenciar o design em um nível estratégico é administrar seus resultados para o processo de uma formulação planejada, contribuindo na cultura organizacional da empresa (MOZOTA, 2011). A gestão do design contribui para a inovação e desenvolvimento de produtos e serviços. Segundo Santos (2000), a gestão do design permite que as empresas continuem aperfeiçoando seus produtos e desenvolvam novos com maiores possibilidades de sucesso. Nas atribuições da gestão do design, está o processo de construção de uma marca para identificação de empresas e produtos.

A marca identifica os produtos e serviços, assim como comunica a identidade da empresa. Um dos objetivos do uso da marca é de diferenciar uma empresa do seu concorrente às vistas do consumidor. Para Perez (2004) uma marca faz uma conexão 
simbólica entre a organização, seu produto e o mercado de consumo. Isso pode ocorrer pelo nome, signo visual, meio auditivo, meio escrito ou com a combinação de todos.

Para Kotler e Pfoertsch (2008) a construção da marca vai muito além de criar consciência de seu nome e das promessas aos clientes. É uma jornada para a construção de uma alma coorporativa e da comunicação desse sentimento a todos os seus sócios como um vírus por dentro e por fora da empresa, de maneira que os clientes recebam realmente tudo aquilo que a marca promete. Irigaray, et al (2004), diz que a marca de um produto ou de uma empresa não é apenas o seu nome, mas tudo (ou qualquer coisa) que faça os consumidores identificá-los.

Para muitas empresas a marca tem um valor significativo como uma propriedade legal de grande valor, que de alguma forma influencia o comportamento do consumidor de comprar, vender e ainda oferecer segurança de receitas futuras e estáveis para seu proprietário.

Quando diversos fatores estão envolvidos no processo de venda, a gestão da marca é fundamental. Com tantas ofertas, o consumidor esta mais atendo às informações sobre os produtos e às marcas para fazer suas escolhas. Então as empresas devem estar atentas à formulação de politicas internas e externas empregadas na formulação da sua identidade corporativa.

\subsection{O varejo como ponto de contato da empresa com o consumidor}

O varejo é um dos principais canais de distribuição das empresas fabricantes de objetos. Segundo a Keller e Machado (2006) o varejo é definido como o lugar onde se pratica negócios de compra e venda de pequenas quantidades de mercadorias, aberto e frequentado pelo público em geral e o lugar onde acontece o armazenamento e exibição de produtos.

O modelo convencional de venda é o físico, onde o vendedor geralmente participa no processo de venda, informando as características das mercadorias e sendo a porta voz da marca. Algumas marcas expandiram seus canais também para o varejo on-line e hoje trabalham com lojas físicas e também com vendas no ambiente virtual. O ambiente virtual deve também trazer todas as facilidades em obter a informação sobre o produto e empresa, assim como o físico. Isso possibilita ao consumidor o poder de optar onde quer comprar os produtos.

No branding, o varejo é um dos principais canais de relacionamento entre a empresa e o seu cliente.

\subsection{O papel do branding na diversificação dos canais de varejo}

Para Wheeler (2012),
A gestão de marcas, também chamada de branding, é um processo disciplinado para desenvolver a conscientização e ampliar a fidelidade do cliente, exigindo determinação superior e disposição apara investir no futuro. A ideia da gestão de marcas é aproveitar todas as oportunidades para expressar por que as pessoas deveriam escolher uma marca e não outra. O desejo de liderar, de superar a concorrência e de dar aos colaboradores as melhores ferramentas para se comunicarem com os clientes é o motivo pelo qual as empresas utilizam a gestão de marcas.

Segundo Kapferer (2003), para a marca ser percebida pelo usuário ela precisa 
mostrar o seu valor e ser reconhecida pelo seu público como algo que justifique sua atratividade e preço. Uma marca atrativa se apresenta à frente do seu concorrente, se tornando uma referência em sua categoria.

Na tabela abaixo Kapferer (2003) lista as funções da marca e os benefícios que elas trazem ao consumidor. Para o autor a marca tem a função de referência, praticidade, garantia, otimização, personalização, permanência, hedonista e ética.

Tabela 1 - Percepção da marca pelo consumidor.

\begin{tabular}{|l|l|}
\hline Função da marca & Benefícios que trazem aos consumidores \\
\hline De referência & $\begin{array}{l}\text { Permite a visualização clara, a identificação rápida dos produtos que o } \\
\text { consumidor procura. }\end{array}$ \\
\hline De praticidade & $\begin{array}{l}\text { O consumidor poupa tempo e energia ao recomprar um produto por ser } \\
\text { fiel à marca. }\end{array}$ \\
\hline De garantia & $\begin{array}{l}\text { Segurança de encontrar uma qualidade estável em todos os lugares e a } \\
\text { todo o momento. }\end{array}$ \\
\hline De otimização & $\begin{array}{l}\text { Segurança de comprar o melhor produto de sua categoria, com o melhor } \\
\text { desempenho para um uso especifico. }\end{array}$ \\
\hline Personalização & $\begin{array}{l}\text { Sentisse reconfortado com sua auto-imagem ou com a imagem que é } \\
\text { passada aos outros. }\end{array}$ \\
\hline De permanência & $\begin{array}{l}\text { Quando o consumo da marca durante longos anos traz ao consumidor } \\
\text { familiaridade e intimidade. }\end{array}$ \\
\hline Hedonista & Satisfação ligada à estética da marca, seu design e suas comunicações \\
\hline Ética & $\begin{array}{l}\text { Quando o comportamento responsável da marca perante a sociedade traz } \\
\text { satisfação ao comprador. }\end{array}$ \\
\hline
\end{tabular}

Fonte: (KAPFERER, 2003)

A partir das informações acima, podemos perceber a importância que uma marca representa tanto para o comprador como para as empresas.

Para Aaker (2000) uma marca forte é aquela que tem uma identidade de marca clara e valiosa. Essa identidade deve estar presente de maneira unificada em todos os canais onde ela se apresenta. Incluindo os canais de varejo on-line e físicos.

O varejo físico, quando representado por uma loja, se utiliza de diversas táticas para garantir o envolvimento do consumidor na imersão do universo da marca. Existem pesquisas em visual merchandising que estudam e apresentam as melhores práticas na estruturação de uma comunicação aplicada ao espaço construído.

Hoje em dia, o comércio eletrônico movimenta uma quantia monetária considerável quando bem gerenciado. Por isso é um caminho estratégico para a ampliação do mercado para muitas marcas. Para que a empresa possa se apresentar por ele de maneira eficiente, esta deve ter cuidado em apresentar uma comunicação integrada com o que já é informado no seu varejo físico.

Para Shmitt, Simonson (2000) o varejo on-line é uma ferramenta essencial na comunicação da identidade corporativa, marca e criação de imagem. É onde se pode explorar textos, elementos visuais, áudios e vídeos.

Os varejistas devem ter como intuito proporcionar uma comunicação única em seus canal de vendas e que esta traga o contexto da marca aplicado de maneira clara para o cliente.

Percebendo a importância do branding ser refletido nas comunicações dos canais de varejo que esta pesquisa visa analisar, de maneira comparativa, a 
comunicação das lojas on-line e físicas de uma empresa do segmento de acessórios de decoração. Denominaremos essa marca de Empresa A para proteger a sua identidade. Este trabalho servirá como base para a realização de trabalhos semelhantes junto à outras empresas.

Essa análise comparativa justifica-se pelo fato de que a marca é muito importante estrategicamente para a empresa. É com ela que os consumidores irão distingui-la dos concorrentes. Com a comunicação do branding bem estruturada ela pode ser identificada pelos seus clientes tanto no varejo online quanto no físico. A gestão do design da marca é o ponto principal para manter uma boa aplicação do branding nos canais de venda, tanto na loja física como na loja on-line. 0 reconhecimento da marca pelo cliente pode levar a empresa a ter uma imagem forte no mercado. Isso pode ser decisivo no processo de compra pois, como vimos na tabela de Kapferer (2003), a marca fornece vários benefícios aos consumidores.

\section{METODOLOGIA}

Este artigo tem como objetivo analisar os aspectos da comunicação do branding de uma empresa em dois ambientes distintos, no varejo on-line e físico, utilizando uma análise comparativa. $O$ estudo tem caráter exploratório através do método dedutivo, onde o mesmo tem base em artigos científicos, livros e artigos publicados em congressos. Para Gil (2002) a pesquisa exploratória proporciona uma aproximação com o tema e o levantamento bibliográfico, entrevista com envolvidos com a problemática, e análise de exemplos, podendo assumir a forma de uma pesquisa bibliográfica ou um estudo de caso. $O$ artigo apresenta um estudo de caso como referencia da aplicação do assunto estudado.

No estudo de caso foram comparados:

a) Elementos de identificação: (1) fachada, (2) vitrine, (3) zona de transição e (4) área interna.

Os elementos observados foram relacionados às cores, produtos, comunicações e demais itens configurativos. Os elementos de identificação 1,2 e 4 foram determinados segundo o autor Malhotra (2013) e o 5, zona de transição, é um termo, cunhado pelo autor Underhill (2004). Esta área refere-se àquele espaço da loja imediatamente após a entrada. Podem existir neste espaço vários estímulos, como sinalização de localização, comunicações, exposição de produtos e ocupações variadas do espaço.

Para realizar a análise comparativa com o e-commerce, foram-se estabelecidos os seguintes critérios:

- Fachada: página home. A primeira página ao acessar um site.

- Vitrine: Banners e demais elementos de destaque visíveis na parte superior da home.

- Zona de transição: o site da home da Empresa A apresentou-se bastante alongado, mostrando, no rolar da página, muitos produtos categorizados e em destaque. Este espaço será compreendido como zona de transição.

- Área interna: as páginas internas do site. 


\section{ESTUDO DE CASO}

\subsection{Sobre a empresa}

A empresa, que vamos chamar de Empresa $A$, analisada possui sua sede na cidade de Florianópolis, em Santa Catarina. Nesta sede fica o setor administrativo, com profissionais das áreas de design, visual merchandising, marketing e administração. Cada equipe possui suas funções distintas, mas também trabalham em campanhas comuns, visando a integração das estratégias da empresa.

A empresa também possui um departamento responsável pela atividades de concessão de franquias e suas administrações. Este departamento presta consultoria aos franqueados, além de suporte aos softwares necessários para a gestão do negócio.

$\mathrm{Na}$ cidade de Teresópolis, Rio de Janeiro, existe um escritório que trata dos assuntos de logística. Os funcionários deste espaço são responsáveis pelas operações de compra, venda e distribuição de produtos para todo o Brasil.

A Empresa A, em questão, está no mercado há 24 anos, tem 300 funcionários e lança 400 produtos por ano. O faturamento da rede em 2014 foi de $\mathrm{R} \$ 190$ milhões.

Os produtos da Empresa A são do segmento de utilidades para casa, segundo o site da marca. Os produtos são criados pensando em coleções, onde diversos fatores estão envolvidos como a análise do estoque existente, histórico de vendas, produtos com maior popularidade e público alvo, por exemplo. Também são desenvolvidos produtos para coleções sazonais e datas comemorativas, como para o dia dos pais, dia dos namorados, natal e dia das crianças.

\subsection{Análise da gestão da marca entre o e-Commerce e a loja física}

Após ser realizado o processo metodológico anteriormente descrito, as informações coletadas, foram tabuladas e estão apresentadas na tabela 2 abaixo: 
Tabela 2 - Análise comparativa dos elementos de comunicação entre e-Commerce e loja física

\begin{tabular}{|c|c|c|}
\hline & e-Commerce & Loja física \\
\hline Fachada / home & $\begin{array}{l}\text { Na home encontramos diversos elementos } \\
\text { gráficos que estão alinhados ao conceito da } \\
\text { marca e à identidade padrão da empresa. A } \\
\text { página é estruturada de maneira que no topo } \\
\text { existe a marca da empresa. Seguida pelo menu } \\
\text { de navegação por categorias. A logo fica } \\
\text { evidenciada à direita e este cabeçalho. As cores } \\
\text { preta e branca, predominam no cabeçalho do } \\
\text { site. São as cores da marca. O cinza também }\end{array}$ & $\begin{array}{l}\text { O letreiro superior à porta de entrada identifi- } \\
\text { ca a empresa. A logo está à direita e apresen- } \\
\text { ta-se identica à que está no site. Predominam } \\
\text { o preto e o branco. A cor preta é a mais } \\
\text { presente pois pigmenta toda a fachada. Há a } \\
\text { aplicação de uma placa amarela junto à logo, } \\
\text { cor esta que destoa do que é apresentado no } \\
\text { site. Novamente aqui vê-se muitas linhas } \\
\text { retas. }\end{array}$ \\
\hline
\end{tabular}
aparace apresentando os menus. branco é 0 mais presente, pois é a cor do fundo do site. $\mathrm{O}$ azul é uma cor auxiliar que aparece para destacar algumas palavras. Quanto às formas, predominam as linhas retas.

Vitrine/Banners Abaixo do menu encontra-se um banner promocional randômico com nove tipos diferentes de promoções. (1) compre e ganhe brinde, cor predominante azul, (2) Clássicos, cor predominante amarela, (3) Clássicos em promoção, cor predominante rosa, (4) Produtos Geek, cor predominante vermelha, (5) Lançamentos, cor predominante amarela, (6) Linha Star Wars, cor predominante preta, (7) Linha Snoop, cor predominante amarela, (8) Descontos, cor predominante rosa e (9) Coleção tropical, cor predominante amarela. Junto ao banner principal, embaixo, está um banner fixo com informações de frete, parcelamento, oferta do dia e política de devolução.

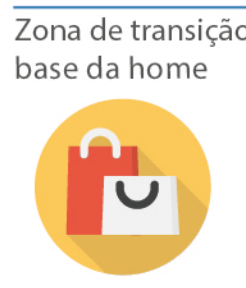

Abaixo vem a apresentação dos produtos de destaque, separados em categorias em uma grid de quatro colunas e vinte e seis linhas. Cada linha dá destaque à um grupo de produtos. A cor branca é a mais presente pois é a cor do fundo do site. $\mathrm{O}$ cabeçalho com a logo acompanha fixo durante a rolagem. O rodapé conta com links para informações por categorias: loja virtual, institucional e negócios. Chat e contato estão à esquerda, em destaque com a cor azul aplicada na fonte. Fora o azul, todo o restante do rodapé é em cinza, branco e preto. Os links para as mídias sociais são as últimas a serem mostradas, bem discretamente.

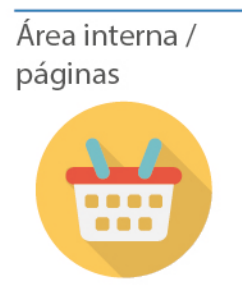

Voltando ao menu superior, existem links para páginas centrais. Para exemplificar, entramos em "eletrônicos", porém todas as páginas são bastante semelhantes quanto a organização. Os produtos são apresentados em um tamanho de $100 \times 100$ px de maneira geral. São três colunas de fotos com linhas contínuas, até finalizar a apresentação de todos os produtos . Quando selecionados, os produtos apresentam um link para aumentar o tamanho da sua imagem, onde podem ser observados seus detalhes.

As fotos mostram algumas vistas para melhor serem entendidos visualmente. Há também áreas de texto explicando as características do produto, valor e políticas de venda. Novamente há predominancia de branco em todo o fundo da página. O cabeçalho permanece fixo, apresentando a marca.

Um dos grandes destaques da loja é a iluminação sobre os objetos e em partes onde existe uma comunicação promocional. O espaço conta com spots direcionados principalmente para as prateleiras. Na parte superior/central existe um sistema de iluminação geral do ambiente. Na parte interna da loja o layout é dividido em coleções. Os mobiliários são discretos, pretos, retos, o que faz ressaltar o design dos objetos expostos. Alguns equipamentos estão ligados para que o cliente possa experiênciar antes de comprar. Os vendedores auxiliam os clientes e apresentam os produtos, informando basicamente as mesmas características que são encontradas na descrição no site. O caixa de pagamento fica ao fundo da loja. Ali também são armazenados os materiais necessários para embalar para presente. Percebe-se que algumas informações presentes nos banners principais do site são negligenciados, cabendo às vendedoras informar ao cliente. Como o banner 1, compre e ganhe brinde.

Fonte: Elaborado pelo autor, com base na pesquisa realizada. 


\subsection{Análise da tabela comparativa}

Tanto no e-Commerce como na loja física da Empresa A são aplicados elementos que remetem ao conceito da marca e às formas que fazem parte da identidade visual da empresa. Nesses ambientes são trabalhados aspectos do branding de maneira visível e de maneira semelhante, porém com alguns desvios.

Tabela 3 - Semelhanças e diferenças entre os canais de varejo analisados

\begin{tabular}{|c|c|c|}
\hline & Semelhanças & Diferenças \\
\hline Fachada / home & $\begin{array}{l}\text { - A logo tem a mesma grafia e cor. É até mesmo } \\
\text { proporcional ao entorno nas duas aplicações. } \\
\text { Apresenta-se localizada no e-Commerce em } \\
\text { uma posição semelhante ao local que é localiza- } \\
\text { da na fachada da loja física. } \\
\text { - As cores da marca estão presentes nos dois } \\
\text { canais de varejo. O preto e o branco são as cores } \\
\text { mais utilizadas. } \\
\text { - As linhas retas e as formas retangulares estão } \\
\text { presentes em ambas. }\end{array}$ & $\begin{array}{l}\text { - Presença de cinza e azul no cabeçalho da } \\
\text { home e do amarelo na fachada da loja física } \\
\text { diferem as cores auxiliares da marca. }\end{array}$ \\
\hline Vitrine / Banners & $\begin{array}{l}\text { - A Coleção tropical, presente no banner } 9 \text { no } \\
\text { e-Commerce é a única que está presente na } \\
\text { vitrine. A cor predominante amarela do banner } \\
\text { digital também aparece na parede de fundo da } \\
\text { vitrine, plotado em adesivo e colado em mate- } \\
\text { rial rígido. As mensages e os elementos visuais } \\
\text { são semelhantes. }\end{array}$ & $\begin{array}{l}\text { - A não mensão às promoções dos outros } \\
\text { banners encontrados no site podem decep- } \\
\text { cionar alguns clientes. } \\
\text { - As políticas de devolução e pagamento não } \\
\text { aparecem e somente são oralizadas pelos } \\
\text { atendentes. }\end{array}$ \\
\hline $\begin{array}{l}\text { Zona de transição / } \\
\text { base da home }\end{array}$ & $\begin{array}{l}\text { - Os produtos são os únicos elementos seme- } \\
\text { lhantes. }\end{array}$ & $\begin{array}{l}\text { - Esta parte do e-Commerce é bastante seme- } \\
\text { lhante ao layout de outros sites, inclusive de } \\
\text { empresas concorrentes. O cabeçalho fixo com } \\
\text { a logo acompanhando durante a rolagem é o } \\
\text { único elemento que auxilia na identificação } \\
\text { da marca. Não há qualquer semelhança com a } \\
\text { zona de transição da loja física, que é bem } \\
\text { escura e sem a presença da logo da empresa. } \\
\text { - O rodapé apresenta as cores cinza e azul. } \\
\text { Este azul não aparece na loja física. }\end{array}$ \\
\hline $\begin{array}{l}\text { Área interna / } \\
\text { páginas }\end{array}$ & $\begin{array}{l}\text { - A marca aparece nos precificadores e em } \\
\text { algumas comunicações promocionais junto aos } \\
\text { produtos na loja física. A logo é a mesma que } \\
\text { está presente no site no cabeçalho fixo. }\end{array}$ & $\begin{array}{l}\text { - A organização dos produtos distoa do apre- } \\
\text { sentado no site. } \\
\text { - Quanto ao pano de fundo para os produtos, } \\
\text { a loja física é integralmente preta com móveis } \\
\text { pretos e o e-Commerce é integralmente } \\
\text { branco. }\end{array}$ \\
\hline
\end{tabular}

Fonte: Elaborado pelo autor, com base na pesquisa realizada.

O e-Commerce da Empresa A tem suas características visuais perceptivelmente relacionados à sua identidade visual, tendo, de maneira geral, um modelo para aplicação de cores, formas e padrões gráficos. Para o consumidor, aspectos como esses estão ligados à qualidade e organização. Para a empresa isso representa uma imagem coesa com o proposto na gestão do design da marca.

Um ponto a ser destacado é o fato da loja virtual não ser adaptada para multiplataformas (celular, smartphones, smart-tv e tablets). Ficando extremamente distorcida, dificultando a navegação e, consequentemente, a compra. Desta maneira, a análise foi baseada majoritariamente nas observações da página web da Empresa $A$ acessada por computador pessoal. No momento atual, as empresas devem estar integradas ao contexto do consumidor e este está cada vez mais conectado ao mundo virtual por meio de equipamentos diferentes do computador ou notebook. As empresas devem pensar nas diversas formas de interação do consumidor com a sua 
página na web e na variedade dos dispositivos utilizados para tal (SHMITT, SIMONSON, 2000).

Percebeu-se na loja física da Empresa A uma atmosfera mais envolvente da marca. Existe um forte apelo visual para divulgar seus produtos, recorrendo até a formas lúdica na comunicação e iluminação de destaque (spot direcionado). Para atrair o consumidor a marca utiliza elementos que refletem sua personalidade de maneira mais explícita. Os vendedores e som ambiente auxiliam neste processo. Além de uma arquitetura tendendo ao estilo Industrial, não aparente no $e$-Commerce.

Seguem o que diz Aacker (2000), de que uma loja não deve apenas oferecer as melhores ofertas e oportunidades, mas a experiência e o conceito da marca aplicado em todo seu interior, permitindo ao consumidor que veja a identidade visual e sua aplicação.

Essa atmosfera da marca não é tão presente no e-Commerce. Talvez esteja neste aspecto o maior desafio dos varejistas na atualidade, fazer o consumidores ter as mesmas impressões que tem na loja física, também no ambiente on-line.

\section{CONSIDERAÇÕES FINAIS}

Durante o processo de pesquisa foi possível observar a preocupação da empresa com a gestão do design da marca e a grande integração dos quesitos de branding entre o e-commerce e o loja física. Foi possível também compreender que é possível uma aplicação pratica da teoria sobre a gestão do design da marca.

A gestão do design da marca no varejo on-line e físico deve também estar relacionada a uma preocupação contínua das empresas para desenvolver uma imagem referência em seu segmento para aproximar o seu consumidor.

Há neste estudo a visão de uma nova oportunidade de atuação para os designers dentro das corporações. A gestão do design vem trazer o caráter de especialização do profissional do design, trabalhando de forma holística. Como visto neste artigo, essa gestão do design pode ser aplicada na relação da marca com o varejo online e físico.

Pode-se observar também a interdisciplinaridade de várias áreas para uma boa comunicação do branding no varejo, como, por exemplo, a área de design gráfico, design de produto, arquitetura e design de interiores.

\section{REFERÊNCIAS}

AAKER, A. David; JOACHIMSTHALER, Erich. Como Construir Marcas Líderes. São Paulo, Editora Futura, 2000.

BLESSA, Regina. Merchandising no Ponto de Venda. São Paulo: Atlas, 2001.

Centro Brasil Design. Diagnóstico do Design Brasileiro. CBD, MDIC, APEX, 2014.

Disponível em: <http://www.mdic.gov.br/arquivos/dwnl_1402666459.pdf>. Acesso em 20 de agosto de 2015.

CHAMMA, Lelé Norberto; PASTORELO, Dominguez Pedro. Marcas e Sinalização: práticas em design corporativo. São Paulo: Editora Senac, 2007.

DEMETRESCO, Sylvia. Vitrinas em Diálogos Urbanos. São Paulo: Editora Anhembi Morumbi, 2005. 
GIL, A. C. Como elaborar projetos de pesquisa. São Paulo, 2002.

GURGEL, Miriam. Projetando espaços: guia de arquitetura de interiores para áreas comerciais. São Paulo: Editora Senac, 2013.

IRIGARAY, H. A. et al. Gestão e desenvolvimento de produtos e marcas. Rio de Janeiro: Editora FGV, 2004.

KAPFERER, Jean-Noël. As marcas, capital da empresa: criar e desenvolver marcas fortes. Porto Alegre: Bookman, 2003.

KAPFERER, J. Marcas à prova de prática: aprendendo com os erros. Tradução técnica: Carolina Huang. 2.ed. Porto Alegre: Bookman, 2004.

KAPFERER, J. $\mathbf{O}$ que vai mudar as marcas. Tradução técnica: Carolina Huang. Porto Alegre: Bookman, 2004.

KELLER, K.L.; MACHADO, M. Gestão estratégica de marcas. Tradução técnica: Arlete Simille Marques. São Paulo: Pearson Prentice Hall, 2006.

KOTLER, P.; PFOERTSCH, W. Gestão de marcas em mercados B2B. Tradução técnica: Raul Rubenich. Porto Alegre: Bookman, 2008.

KURACZ, Anie. Avaliação dos Fatores de Análise do Comportamento do Consumidor Imaginarium. Trabalho de conclusão de curso - Programa de graduação do curso de Bacharelado em Administração, do Centro Sócio Econômico - Universidade Federal de Santa Catarina, 2009.

MALHOTRA, Naresh. Design de loja e Merchandising Visual. Tradução Arlete Simille. São Paulo: Saraiva, 2013.

MOZOTA, Brigitte Borja de; KLÖPSCH, Cássia; COSTA, Felipe C. Xavier da. Gestão de Design: usando o design para construir valor de marca e inovação corporativa. Porto Alegre: Bookman, 2011.

PEREZ, Clotilde. Signos da marca: expressividade e sensorialidade. São Paulo: Pioneira Thomson Learning, 2004.

PINHEIRO, Perrone Eduardo; GULLO, José. Comunicação Integrada de Marketing. 2 . Ed. São Paulo: Editora Atlas, 2005.

SANTOS, Anthero Flávio. O Design Como Diferencial Competitivo. Itajaí: Editora UNIVALI, 2000.

SCHMITT, Bernd; SIMONSON, Alex II. A estética do marketing. São Paulo: Nobel, 2000. UNDERHILL, Paco. A magia dos Shoppings. Rio de Janeiro: Elsevier, 2004.

WHEELER, Alina. Design de identidade da marca-: Guia Essencial para Toda a Equipe de Gestão de Marcas. Bookman Editora, 2012. 